\title{
A Meta-Analysis Of Organizational Citizenship Behavior And Leader-Member Exchange
}

\author{
Jeannie Scott, (Email: scott@uiwtx.edu), University of the Incarnate Word \\ Annette E. Craven, (Email: craven@uiwtx.edu), University of the Incarnate Word \\ Connie Green, (Email: greenc@uiwtx.edu), University of the Incarnate Word
}

\begin{abstract}
Numerous studies on Leader-Member Exchange (LMX) Theory of leadership have identified various antecedents and consequences of LMX. This study is a meta-analysis (Hunter \& Schmidt, 1990) of two variables-organizational citizenship behavior and leader member exchange. The study addresses the following questions: (a) What is the correlation between organizational citizenship behavior and leader-member exchange? (b) What are the effects of moderators such as employee status, supervisory status, tenure, and perceptions outside of the United States?
\end{abstract}

\section{INTRODUCTION}

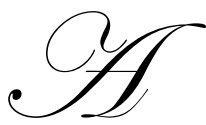

s American business companies struggle with the pressure from takeovers, mergers, restructuring, and acquisitions, employees' citizenship behavior is changing because employees perceive a lack of job security in the workplace. Before corporate downsizing, layoffs, and unemployment became common practice in the business world, there had been inherent expectations by management of employees' organizational citizenship behavior in the workplace.

Organizational citizenship is behavioral, wherein subordinates accommodate their supervisors, other employees, and clients in the conduct of their assigned duties by performing what is normally expected such as not arriving late, not leaving early, and not abusing their lunch break. Organizational citizenship behaviors are extra-role behaviors which, when performed by the members of the organization, benefit the organization (Bateman \& Organ, 1983). These are everyday acts of cooperation that go beyond the formal job description (Katz \& Kahn, 1978). The challenge for management is how to foster citizenship behavior within their employees despite the reality of job cuts in the workforce. There is considerable research to suggest interpersonal interaction between supervisors and subordinates merits closer scrutiny.

The Leader-Member Exchange (LMX) Theory is a well-researched leadership construct in organizational behavior and business management studies. Leader-Member Exchange is a two-way relationship (dyad) between the Leader (supervisor) and the Member (subordinate) (Danserau, Graen, \& Haga, 1975; Deluga, 1998; Graen \& Cashman, 1975; Graen \& Scandura, 1987; Graen \& Schiemnann, 1978; Vecchio \& Gobdel, 1984). The theory asserts that leaders treat each employee on a different level of social exchanges, i.e., supervisors do not interact with subordinates uniformly (Graen \& Cashman, 1975; Wayne \& Green, 1993). The quality of the relationship or exchange varies because supervisors have limited time and resources. Supervisors exchange personal and positional resources in return for subordinates' performance on unstructured tasks. These personal and positional resources are: sharing of socalled inside information, influence in decision-making, task assignment, job latitude, support, and attention (Graen \& Cashman, 1975).

Much has been written about LMX Theory and the implications that it has for various aspects of organizational life. For example, LMX research has involved areas such as performance appraisal (Linden, Wayne \& Stilwell, 1993; Wayne \& Ferris, 1990), worker productivity (Scandura \& Graen, 1984), organizational climate 
(Kozlowski \& Doherty, 1989), demographic similarity (Linden et al., 1993), and perceived similarity (Linden et al., 1993; Turban, Jones, \& Rozelle, 1990). As evidenced by the widespread application of LMX Theory, this theory is a useful tool for understanding the dynamics of dyadic functioning in organizational settings.

\section{STATEMENT OF THE PROBLEM}

Numerous studies on Leader-Member Exchange (LMX) Theory of leadership have identified various antecedents and consequences of LMX. This study is a meta-analysis (Hunter \& Schmidt, 1990) of two variablesorganizational citizenship behavior and leader member exchange. The study addresses the following questions: (a) what is the correlation between organizational citizenship behavior and leader-member exchange? (b) what are the effects of moderators such as employee status, supervisory status, tenure, and perceptions outside of the United States?

An analysis of the total sample was performed using uncorrected and corrected effect sizes. The effect sizes for each study in the meta-analysis were corrected for study artifacts as identified by Hunter and Schmidt (1990). These artifacts included: sampling error, error of measurement in the dependent and independent variables, dichotomization of continuous independent and dependent variables, range variation, attrition, deviation from perfect construct validity in the dependent and independent variables, transcription errors, and variance due to extraneous factors (Hunter \& Schmidt, 1990). In addition to examining the sample as a whole, three-moderator analysis was run to determine their effect on the variables of interest. The moderator analysis will include: (a) tenure (less than 5 years or greater than 5 years, (b) study conducted in the United States or another country, (c) employee or supervisory status.

The study of OCB explores the nature of discretionary behaviors of employees in the work place. OCB has a social exchange phenomenon and has been linked to LMX (Duarte, Goodson, \& Kilch, 1994; Farh, Podsakoff, \& Organ, 1990; Tansky, 1993). Blau (1964) described the differences between social and economic exchange saying, "only social exchange tends to engender feelings of personal obligation, gratitude, and trust; purely economic exchange as such does not" (p. 94); therefore, if employees consider themselves in conditions of social exchange, they exhibit OCB. In addition, theoretical and empirical research supports a positive relationship between OCB and group level performance outcomes (Karambayya, 1989; Smith, Organ, \& Near, 1983).

Leader-Member Exchange Theory (Graen, Novak, \& Sommerkamp, 1982), originally named Vertical Dyad Linkage Model (Dansereau, Graen, \& Haga, 1975), posits leaders treat their subordinates differently, i.e., relationships or exchanges at varying degrees or levels depending upon whether the latter are part of the in-group (referred to as high-quality exchange relationship) or out-group (low-quality exchange) (Dansereau, Graen, \& Haga, 1975; Graen, 1976; Graen \& Cashman, 1975; Graen, Novak, \& Sommerkamp, 1982; Graen \& Scandura, 1987; Graen \& Uhl-Bien, 1995; Linden \& Graen, 1980). A social exchange process evolves between supervisor and subordinate in the development and maintenance of the following personal characteristics: mutual trust, interdependency, shared support, respect, strong loyalty, and reciprocal influence (Graen \& Cashman, 1975). As noted by Deluga (1998), the dynamics in the dyadic exchange of the supervisor and subordinate result in either high-quality or low-quality Leader-Member Exchange relationship.

\section{LITERATURE REVIEW}

A review of the Leader-Member Exchange literature agrees with the notion that leaders treat subordinates differently at varying degrees and levels (Dienesch \& Linden, 1986), contingent on whether the latter are part of the in-group (high-quality relationship) or out-group (low-quality relationship) (Dansereau, Graen, \& Haga, 1975; Graen, 1976; Graen \& Cashman, 1975; Graen, Novak, \& Sommerkamp, 1982; Graen \& Scandura, 1987; Linden \& Graen, 1980; Scandura \& Graen, 1984; Vecchio, 1982). Proponents of the theory assert the quality (in-group or out-group) of dyadic exchange between superior-subordinate is more predictive of positive organizational outcomes than the leader's traits or behaviors (Gerstner \& Day, 1997; House \& Aditya, 1997). The in-group reports mutual respect, trust, shared support, interdependencies, greater job latitude, common bonds, open communication, and reciprocal obligation between the supervisor and the subordinate (Dienesch \& Linden, 1986; Linden \& Graen, 1980; Snyder, 
Williams, \& Cashman, 1984). The exchange between superior-subordinate (dyad), is the unique basic premise and the unit of analysis of the Leader-Member Exchange (Graen, 1976; Linden \& Graen, 1980).

The study of OCB explores the nature of discretionary behaviors in the work place. OCB emphasizes the social context of the work environment in addition to the technical nature of the job. OCB has been defined in terms of pro-social behavior (Brief \& Motowidlo, 1986; Puffer, 1987), altruism (Rosch, 1978), and service orientation (Hogan \& Busch, 1984). Several studies (Organ \& Konovsky, 1989; Smith, Organ, \& Near, 1983) have empirically labeled an altruistic OCB component that includes such employee behaviors as volunteering for things that are not required and making innovative suggestions to improve the department. Researchers have linked need for achievement, education, job satisfaction, urban and rural background, task scope, perceived peer competition, group cohesiveness, leader fairness, employee positive affect and negative affect, and employee positive mood to altruistic OCB (Farh, Podsakoff, \& Organ, 1990; Organ \& Konovsky, 1989; Puffer, 1987; Smith et al., 1983). Smith et al. (1983) also isolated a general compliance OCB component now relabeled conscientiousness (Organ, 1990), which includes such behaviors as not coasting toward the end of the day and having work attendance above the norm. Conscientiousness OCB has been associated with need for achievement, years of service, urban and rural background, task scope, and affect (Organ \& Konovsky, 1989; Puffer, 1987; Smith et al., 1983). Organ (1990) contended that both types of OCB, altruistic and conscientiousness are generated primarily as a result of social exchange that characterizes much of human interaction.

In his concept of "willingness to cooperate," Barnard (1983) linked the concept to another important concept, the informal structure that set him apart from much of the accepted thought of his day concerning organizations. In that era, the prevailing concepts of the organization constituted what is generally known today as Classical Management Theory (Organ, 1990). Classical writers assumed that most participants in organizations possessed neither the capacity nor the disposition to cooperate spontaneously. Only formal structure and controls, as defined and enforced by management, could fulfill this function (Organ, 1990). Barnard (1983) held that formal structure is the result, not the cause, of organized activity. He also contended that formal structure could only recognize what is already inherent in the individual and collective willingness to cooperate. According to Barnard (1983), formal structure does not suffice to anticipate all needed contributions. Willingness to cooperate is the essential condition that must be added to the formal structure. Organ (1990) stated that Organizational Citizenship Behavior is a very important construct in current use that closely resembles Barnard's willingness to cooperate.

OCB consists of informal contributions that participants can choose to proffer or withhold without regard to considerations of sanction or formal incentive (Organ, 1990). According to Organ (1988), OCB has consisted of five specific categories: (a) altruism, which includes all discretionary behaviors that have the effect of helping a specific other person with an organizationally relevant task or problem, (b) conscientiousness, or behavior that organization members carry out certain role behaviors well beyond the minimum required levels, (c) courtesy, which includes such actions as "touching base" with those parties whose work would be affected by one's decisions or commitments, (d) civic virtue, which implies a sense of involvement in what policies are adopted and which candidates are supported, and (e) sportsmanship, or acts that avoid complaining, petty grievances.

\section{LMX And OCB}

Related research supported the argument that LMX should impact OCB. Duarte, Goodson, and Kilch (1994) found high LMX employees were rated more highly on subjective performance. They suggested that one reason for this phenomenon was that employees go beyond their formalized job contracts and contribute more to the work unit through OCBs than can be defined by task completion.

Employee OCB may be related to LMX. Smith, Organ, and Near (1983) identified two dimensions of OCB: altruism and compliance. Altruism refers to behaviors aimed at helping another person such as assisting the supervisor with his or her work, orienting new people and helping others that have been absent. Compliance refers to impersonal behaviors such as not taking undeserved breaks or time off, being punctual and giving advance notice if unable to come to work. Although task performance and OCB are related, there are distinct conceptual differences between the two constructs (Organ, 1988). Task performance includes behaviors that are required through the formal performance 
evaluation. In contrast, OCB is not required or part of the formal reward system. Although OCB is not formally rewarded, OCB may be informally rewarded through LMX (Wayne \& Green, 1993). It seems that an employee who engages in OCB would be contributing to the department's efficiency and effectiveness and helping the supervisor. OCB may be used as a way of reciprocating for support from the supervisor.

Overall these results suggest that LMX should influence occurrences of OCB because LMX is based on interactions between the supervisor and the employee. The linkage between LMX and OCB has been found to be significant (Tansky, 1993). However, this study suffered from several methodological weaknesses. The sample size and response rate were quite small, the control variables had not been shown to be previously linked to OCB, and the validity of the LMX scale employed has been questioned by several researchers (Dienesch \& Liden, 1986; Vecchio \& Gobdel, 1984). Consequently, the precise nature of the LMX and OCB relationship is still unclear.

\section{Meta-Analysis}

Hunter and Schmidt (1990) indicate that meta-analysis, as a research tool, is useful when reviewing related data from numerous studies. Meta-analysis can add to the body of knowledge by using existing studies to reveal cumulative knowledge, identify areas that require more research, and make existing data more easily understood. Lipsey and Wilson (2001) identified four primary advantages of meta-analysis: (a) procedures impose discipline on the process of summarizing research findings, (b) provides a sophisticated approach to aggregating the data, (c) capable of finding effects and relationships in data that are not apparent in other approaches, and (d) provides a way of handling data from numerous studies. Both strengths and weaknesses have been cited when speaking of metaanalysis. Hunter and Schmidt (1990) argue that when using the mean and the standard deviation of the effect size, most criticism of meta-analysis can be overcome.

LMX and OCB Studies: The Following Studies Were Used In This Meta-Analysis

Aryee, S.; Budhwar, P. S.; \& Chen, Z. X. (2002). Trust as a mediator of the relationship between organizational justice and work outcomes: Test of a social exchange model. Journal of Organizational Behavior, 23(3), 267-285.

Deluga, R. J. (1995). The relation between trust in the supervisor and subordinate organizational citizenship behavior. Military Psychology, 7(1), $1-16$.

Donavan, D. T., Brown, T. J., \& Mowen, J. C. (2004). Internal benefits of service-worker customer orientation: Job satisfaction, commitment, and organizational citizenship behavior. Journal of Marketing, 68(1), 128-140

Duarte, N. T., Goodson, J. R., \& Klich N. R. (1993). How do I like thee: Let me appraise the ways. Journal of Organizational Behavior, 14(3), 239-249.

Duarte, N. T., Goodson, J. R., \& Klich N. R (1994). Effects of dyadic quality and duration on performance appraisal. Academy of Management Journal, 37, 499-521.

Farh, J., Podsakoff, P. M., \& Organ, D.W. (1990). Accounting for organizational citizenship behavior: Leader fairness and task scope versus satisfaction. Journal of Management, 705-721

Fok, L. Y. (2000). The relationship between equity sensitivity, growth need strength, organizational citizenship behavior, and perceived outcomes in the quality environment: A study of accounting professionals. Journal of Social Behavior \& Personality, 15(1), 99-120

Konovsky, M. A. \& Pugh, S. D. (1994). Citizenship behavior and social exchange. Academy of Management Journal,37(3), 656-669

Miles, D. E., Borman, W. E., Spector, P. E., \& Fox, S. (2002). Building an integrative model of extra role work behaviors: A comparison of counterproductive work behavior with organizational citizenship behavior. International Journal of Selection and Assessment,10, 51-57

Masterson, S. S., Lewis, K., Goldman, B. M., \& Taylor, M. S. (2000). Integrating justice and social exchange: The differing effects of fair procedures and treatment on work relationships. Academy of Management Journal, 43(4), 738-748

Organ, D. W. \& Lingl, A. (1995). Personality, satisfaction, and organizational citizenship behavior. Journal of Social Psychology, 135(3), 339-52

Riketta, M., \& Landerer, A. (2002). Organizational commitment, accountability, and work behavior: A correlational study. Social Behavior and Personality, 30(7), 653-660

Schappe, S. P. (1998). The influence of job satisfaction, organizational commitment, and fairness perceptions on organizational citizenship behavior. Journal of Psychology, 132(3), 277--292

VanYperen, N. W., \& Van den Berg, A. E. (1999). Towards a better understanding of the link between participation in decision-making and organizational citizenship behavior: A multilevel analysis. Journal of Occupational \& Organizational Psychology, 72(3), 377-394

Organ, D. W. \& Lingl, A. (1995). Personality, satisfaction, and organizational citizenship behavior. Journal of Social Psychology, 135(3), 339-52

Wayne, S. J., \& Green, S. A. (1993). The effects of leader-member exchange on employee citizenship and impression management behavior.

Human Relations, 46(12), 1431-1440

Wayne, S. J., Shore, L. M., \& Linden, R. C. (1997). Perceived organizational support and leader-member exchange: A social exchange perspective. Academy of Management Journal, 40(1), 82-111

Williams, S., Pitre, R., \& Zainuba, M. (2002). Justice and organizational citizenship behavior intentions: Fair rewards versus fair treatment. Journal of Social Psychology, 142(1), 33-34.

Williams, S. \& Shiaw, W. T. (1999). Mood and organizational citizenship behavior: The effects of positive affect on employee organizational citizenship behavior intentions. Journal of Psychology, 133(6), 656-670. 


\section{METHODOLOGY}

Two established instruments; the Leader-Member Exchange (LMX-7) Scale for Leader and Member and the Organizational Citizenship Behavior (OCB) Scale have been used to collect data relevant to understand if there is a correlation between OCB and LMX. During the literature search phase of this study, the criteria included studies of organizational citizenship behavior, perceived leader-member exchange, and perceived leader fairness. Electronic database searches were performed using the following criteria: employee perceptions, leader-member exchange, leader fairness, organizational commitment, organizational justice, commitment, employee relationships, perceived supervisor support, justice, in-group, and out-group.

\section{Meta-Analytic Methods}

Meta-analysis enables the researcher to aggregate data while correcting for artifacts that can bias the effect size estimates (Colquitt, LePine, \& Noe, 2000). Meta-analysis is one technique that allows for the synthesis of data across studies. Nineteen studies were found during the literature search that met the inclusion criteria (see Appendix A for an overview of the studies). These studies were analyzed using the techniques outlined by Hunter and Schmidt (1990). Initially, a bare bone analysis was completed to determine an estimated mean and standard deviation for the corrected population correlations. A moderator meta-analysis was completed for each identified subset of the data. Secondly, the mean correlations and the standard deviation of the correlations were corrected using the formulae outlined in Hunter and Schmidt (1990). The following steps and formulae were used in the bare bones analysis (Ree \& Stauffer, 1996):

1. Computation of the mean: $M_{g}=\sum_{k}^{K} w_{k} g_{k} / \sum_{k}^{K} w_{k}$

2. Compute total variance: $S_{\text {total }}^{2}=\sum_{k}^{K} w_{k}\left(g_{k}-M_{g}\right)^{2} / \sum_{k}^{K} w_{k}$

3. Estimate variance due to artifacts: $S_{\text {error }}^{2}=K\left(\sum_{k}^{K} w_{k}\right)^{-1}$

4. Estimate true variance: $S_{\text {residual }}^{2}=S_{\text {total }}^{2}-S_{\text {error }}^{2}$

The weight for study $k$ is $S_{k}^{-2}$ (inverse of squared standard error). The formula for correlations:

$S_{k}^{2}=\left(1-M_{r}^{2}\right)^{2} /\left(n_{k}-1\right)=w^{-1}$

Each correlation study was then individually corrected using the following formulae:

1. Compute corrected $r:{ }_{c} r=\frac{\frac{r}{a b}}{A B \sqrt{\left(1-u^{2}\right) \frac{r^{2}}{(a b)^{2}}+u^{2}}}$

(If $r_{y y}$ is unrestricted, then $A=r_{y y}{ }^{1 / 2}$ and $a=1$. If $r_{y y}$ is restricted, then $a=r_{y y}{ }^{1 / 2}$ and $A=1$. If $r_{x x}$ is unrestricted, then $B$ $=r_{x x}{ }^{1 / 2}$ and $b=1$. If $r_{x x}$ is restricted, then $b=r_{x x}^{1 / 2}$ and $B=1$.)

2. Compute correction factors $Q$ and $F: Q=\frac{r}{{ }_{c} r}$

$F=\left[\left(\frac{1}{u^{2}}-1\right) \frac{r}{a b}+1\right]$ 
(If $\mathrm{r}_{\mathrm{yy}}$ is unrestricted, then $a=1$. If $r_{y y}$ is restricted, then $a=r_{y y}{ }^{1 / 2}$. If $r_{x x}$ is unrestricted, then $\mathrm{b}=1$. If $r_{x x}$ is restricted, then $\mathrm{b}=r_{x x}{ }^{1 / 2}$.)

3. Compute new weight: ${ }_{c} w_{k}={ }_{c} S_{k}^{-2}=\left(\frac{S_{k}^{2}}{F^{2} Q^{2}}\right)^{-1}$

4. Compute everything else as in a bare bones analysis, except, of course, with corrected values.

The following formulae were used in the noninteractive artifact distribution correlation method:

1. Compute mean and variance for attenuation factors $A, B$, and $C$ : (where $C=\left[\left(1-u^{2}\right) M_{r}+u^{2}\right]^{1 / 2}$ and $D$ is generally any of the three attenuation factors, $A, B$, or $C$ ):

$$
\begin{aligned}
& M_{D}=\sum_{h}^{H} n_{h} D_{h} / \sum_{h}^{H} n_{h} \\
& S_{D}^{2}=\frac{\sum_{h}^{H} n_{h}\left(D_{h}-M_{D}\right)^{2}}{\sum_{h}^{H} n_{h}}
\end{aligned}
$$

2. Compute mean attenuation factor: $F=M_{A} M_{B} M_{C}$

3. Compute mean corrected $r:{ }_{c} M_{r}=\frac{M_{r}}{F}$

4. Compute the sum of the coefficients of variation: $\quad V=\frac{S_{A}^{2}}{M_{A}}+\frac{S_{B}^{2}}{M_{B}}+\frac{S_{C}^{2}}{M_{C}}$

5. Compute corrected variances: ${ }_{c} S_{\text {residual }}^{2}=\frac{S_{\text {residual }}^{2}-\left(M_{r}^{2} V\right)}{F^{2}}$

${ }_{c} S_{\text {total }}^{2}=S_{\text {total }}^{2}$

${ }_{c} S_{\text {error }}^{2}={ }_{c}^{2} S_{\text {total }}-{ }_{c} S_{\text {residual }}^{2}$

The following report statistics are reported:

1. Chi-square: $\chi^{2}=K\left(S_{\text {total }}^{2}\right) / S_{\text {error }}^{2}$

2. Standard error of the mean:

$S E M=\sqrt{S_{\text {error }}^{2} / K} \quad$ (homogeneous case)

$S E M=\sqrt{S_{\text {total }}^{2} / K} \quad$ (heterogeneous case)

3. $Z: Z=M_{g} / S E M$

4. Mean Fisher $z: \quad M_{F z}=\sum_{k}^{K}\left(n_{k}-3\right) F z_{k} / \sum_{k}^{K}\left(n_{k}-3\right)$

5. $Z^{*}: \quad Z^{*}=M_{F z} \sqrt{\sum_{k}^{K}\left(n_{k}-3\right)}$ 


\section{Leader-Member Exchange (LMX-7) Scale}

The LMX-7 Scale is designed to assess the quality of exchange relationship between a supervisor and his or her subordinates. The LMX-7 Scale is a standardized and validated instrument by Scandura and Graen (1984). In their field experiment using controlled groups in pre and post leadership intervention treatments, the internal consistency reliability (Cronbach Alpha) for pre-intervention is .86 and for post-treatment is .84. The stability estimate of the scale (test/retest correlation) is .67. The LMX-7 Leader Scale is designed to be filled out by the supervisor. The Leader Scale consists of seven questions (regarding the supervisor's relationship with his/her subordinates). 0n a 5-point multiple-choice response range tailored to each question. The LMX-7 Member Scale consists of the same basic set of questions with the corresponding referent change to fit the subordinates as the respondents (subordinate rates his/her relationship with the supervisor) on a 4-point Likert response scale. Each of the responses are summed to obtain an overall Leader-Member Exchange score with a possible range of scores from 7 (low) to 35 (high) for leader scores. For members, a score of 7 (low) to 28 (high), with high scores indicating high-quality Leader-Member Exchange relationships between the supervisors and the subordinates. In the Linden et al. (1997) meta-analysis review of 48 studies, 18 of the studies cited LMX-7 Scale as the instrument of choice to measure Leader-Member Exchange.

\section{Organizational Citizenship Behavior (OCB) Scale}

The OCB scale is an instrument designed to measure Organizational Citizenship Behavior. The 16-item scale, of which three items are negatively phrased and reversed-scored, was developed and validated by Smith, Organ, and Near (1983). The three negatively phrased items are: "Takes undeserved breaks; Coasts towards the end of the day; Great deal of time spent with personal phone conversations." Respondents are asked to indicate their agreement on each item using a 5-point Likert-type response range of 1= Never; $2=$ Seldom; $3=$ Occasionally; $4=$ Often; 5= Almost Always. A high total score indicates a subordinate's high level of positive citizenship behaviors. Smith et al. (1983) reported that the scale is a two-dimensional construct that measures the organizational citizenship behavior dimensions of altruism and generalized compliance or conscientiousness. Smith et al. (1983) defined altruistic behavior as "spontaneous charitable acts to specific others," i.e., when an employee helps a co-worker with workrelated tasks (Helps others who have been absent; Volunteers for things that are not required; Orients new people even though it is not required; Helps others who have heavy work loads; Assists supervisor with his or her work; Makes innovative suggestions to improve department), while general compliance or conscientiousness was defined as "impersonal prosocial conduct" (Punctuality; Attendance at work is above the norm; Gives advance notice if unable to come to work; Does not take unnecessary time off work; Does not take extra breaks; Does not spend time in idle conversations). According to Smith et al. (1983), both dimensions "are either not required by law or are essentially unenforceable by the usual incentives or sanctions." The coefficient alpha reliability estimate for altruism is .88 , and the coefficient alpha reliability estimate for generalized compliance citizenship behavior is .85 . This instrument has been used in research by Schappe (1998); Wayne and Green (1993); and Wayne, Shore, \& Linden (1997). The instrument is in the public domain.

\section{RESULTS}

The 19 studies included in this meta-analysis were examined from several different viewpoints. First, the entire sample was analyzed to obtain bare bones and corrected correlation between the two variables of interest, organizational citizenship behavior and leader-member exchange. Both altruism and compliance were considered when analyzing organizational citizenship behavior. A number of moderator studies were then analyzed to determine if one or more variables affected the results. The first moderator examined was whether the study took place in the United States or a foreign country. The second moderator examined included supervisor or subordinate status. Of the nineteen studies, a mixture of only supervisor, only subordinate, or both supervisor and subordinate participating in the study could be found. The third moderator examined was employment tenure (less than 5 years or more than 5 years). The results of the complete sample bare bones and corrected artifact distribution analysis show a correlation between organizational citizenship behavior and perceived leader-member exchange (Table 1). 
Table 1

\begin{tabular}{|c|c|c|c|c|c|c|c|c|c|}
\hline \multirow[b]{2}{*}{ Study } & \multirow[b]{2}{*}{$N$} & \multicolumn{2}{|c|}{ OCB/LMX Correlation } & \multicolumn{2}{|c|}{ OCB Mean } & \multicolumn{2}{|c|}{ OCB $S D$} & \multicolumn{2}{|c|}{ OCB Alpha } \\
\hline & & Altruism & Compliance & Altruism & Compliance & Altruism & Compliance & Altruism & Compliance \\
\hline 1 & 195 & .61 & .70 & 49.38 & 36.20 & 7.49 & 6.93 & .82 & .90 \\
\hline 2 & 98 & .74 & .68 & 4.66 & 5.24 & .77 & .81 & .76 & .66 \\
\hline 3 & 252 & .31 & .45 & 4.75 & 3.09 & .97 & 2.74 & .83 & .93 \\
\hline 4 & 475 & .68 & .70 & 5.50 & 3.90 & 1.00 & 1.14 & .90 & .84 \\
\hline 5 & 96 & .84 & N/A & 9.01 & N/A & .70 & N/A & .87 & N/A \\
\hline 6 & 261 & 77 & .85 & 12.07 & 9.16 & 3.00 & 1.17 & .76 & .85 \\
\hline 7 & 67 & .35 & .40 & 5.67 & 5.76 & 1.01 & 1.09 & .90 & .87 \\
\hline 8 & 42 & .59 & .68 & 8.90 & 9.60 & .72 & .60 & .90 & .90 \\
\hline 9 & 367 & .75 & .62 & 17.61 & 16.15 & 3.16 & 3.78 & .75 & .84 \\
\hline 10 & 114 & .45 & .55 & 5.28 & 4.95 & .71 & .57 & .72 & .65 \\
\hline 11 & 203 & .52 & .54 & 1.42 & 3.46 & 29 & .70 & .87 & .87 \\
\hline 12 & 63 & .84 & .82 & 3.98 & 3.91 & 43 & .70 & .71 & .63 \\
\hline 13 & 130 & .57 & .58 & 5.93 & 3.22 & .90 & .43 & .69 & .69 \\
\hline 14 & 139 & .33 & .42 & 82.20 & 54.20 & 10.60 & 7.60 & .83 & .62 \\
\hline 15 & 142 & .31 & .47 & 5.16 & 4.86 & .76 & .74 & .86 & .76 \\
\hline 16 & 85 & .75 & N/A & 65.38 & N/A & 8.85 & N/A & .87 & N/A \\
\hline 17 & 156 & .77 & .64 & 4.80 & 5.52 & 1.20 & .91 & .91 & .88 \\
\hline 18 & 182 & .86 & .84 & 3.53 & 3.48 & .52 & .58 & .86 & .87 \\
\hline 19 & 653 & .84 & .77 & 4.08 & 3.37 & .49 & .91 & .78 & .74 \\
\hline
\end{tabular}

The uncorrected correlation between organizational citizenship behavior and leader-member exchange for the full sample revealed no significant trends. The heuristic used to determine effect size of the correlation was small $(\mathrm{r} \leq .10)$, medium $(\mathrm{r}=.25)$, and large $(\mathrm{r} \geq .40)$ and was based on the work of Lipsey and Wilson (2001). Further analysis as demonstrated in Tables 2 through 31 shows a high correlation between OCB and LMX.

\section{Domestic/Foreign Moderator Analysis}

The results of the domestic moderator analysis show a correlation between organizational citizenship behavior (altruism) and leader-member exchange. The domestic analysis (altruism) consisted of a sample size of 2,963 in a total of 13 studies. The corrected correlation for domestic (altruism) studies reveals a large correlation between organizational citizenship behavior (altruism) and leader-member exchange. The mean of the bare bones analysis was 0.68 and for the corrected analysis was 0.80 . A $95 \%$ confidence interval places the true correlation between 0.66 and 0.78 and the bare bones correlation between 0.70 and 0.82 . The results of the foreign moderator analysis also show a large correlation between organizational citizenship behavior (compliance) and leader-member exchange. The foreign analysis (compliance) consisted of a sample size of 774 in a total of six studies. The corrected correlation for foreign (compliance) studies reveals a large correlation between organizational citizenship behavior (compliance) and leadermember exchange. The mean $\mathrm{n}$ the bare bones analysis was 0.65 and for the corrected analysis was 0.76 . A $95 \%$ confidence interval places the true correlation between 0.61 and 0.72 and the bare bones correlation between 0.69 and 0.81. Tables 2 and 3 demonstrate the rationale for a corrected mean of .77 for altruism and .77 for compliance.

Table 2: Correlation Artifact Distribution Analysis-Compliance

\begin{tabular}{llcc}
\hline Mean & $=$ & Bare Bones 0.65960 & Corrected 0.77686 \\
\hline Hypothesis-The Case Is Homogeneous; i.e., No Moderators & & & 0.0236979 \\
Total Variance & $=$ & 0.0170838 & 0.0021368 \\
Error Variance & $=$ & 0.0015404 & 0.0215610 \\
Residual Variance & $=$ & 0.0155434 & 9.02 \\
\% of Total Variance Accounted for by Artifacts & $=$ & 9.02 & 188.53 \\
Chi Square (16 df) & 188.53 & \\
\hline Number of Studies=17; Total Sample Size=3,539; Raw (unweighted Mean=0.63000 & & \\
\hline
\end{tabular}


Table 3: Correlation Artifact Distribution Analysis-Altruism

\begin{tabular}{llcc}
\hline Mean & $=$ & Bare Bones 0.66157 & Corrected 0.77442 \\
\hline Hypothesis-The Case Is Homogeneous; i.e., No Moderators: & & & \\
Total Variance & $=$ & 0.0332298 & 0.0455327 \\
Error Variance & $=$ & 0.0016233 & 0.0022243 \\
Residual Variance & $=$ & 0.0316065 & 0.0433084 \\
\% of Total Variance Accounted for by Artifacts & $=$ & 4.89 & 4.89 \\
Chi Square (18 df) & $=$ & 388.93 & 388.93 \\
\hline Number of Studies=19; Total Sample Size=3,720; Raw (unweighted Mean=0.62526 & & \\
\hline
\end{tabular}

The results of the foreign moderator analysis show a correlation between organizational citizenship behavior (altruism) and leader-member exchange. The foreign analysis (altruism) consisted of a sample size of 776 in a total of six studies. The corrected correlation for foreign (altruism) studies also reveals a large correlation between organizational citizenship behavior (altruism) and leader-member exchange. The mean in the bare bones analysis was 0.58 and for the corrected analysis was 0.68 . A $95 \%$ confidence interval places the true correlation between 0.53 and 0.62 and the bare bones correlation between 0.63 and 0.73 . The results are shown in Tables 4 through 11 .

Table 4: Domestic/Foreign Moderator Analysis-Compliance

\begin{tabular}{|c|c|c|c|c|c|c|c|c|}
\hline Study & $r$ & $N$ & $S E$ & $t$ & $a$ & $b$ & $c$ & $r c$ \\
\hline 2 & 0.680 & 98 & 0.057 & 9.087 & 0.900 & 0.943 & $* * *$ & \\
\hline 3 & 0.450 & 252 & 0.035 & 7.967 & 0.900 & 0.943 & $* * *$ & \\
\hline 4 & 0.700 & 475 & 0.026 & 21.318 & 0.900 & 0.943 & $* * *$ & \\
\hline 5 & 0.850 & 261 & 0.035 & 25.968 & 0.900 & 0.943 & $* * *$ & \\
\hline 6 & 0.400 & 67 & 0.069 & 3.519 & 0.900 & 0.943 & $* * *$ & \\
\hline 8 & 0.620 & 367 & 0.029 & 15.097 & 0.900 & 0.943 & $* * *$ & \\
\hline 9 & 0.550 & 114 & 0.053 & 6.969 & 0.900 & 0.943 & $* * *$ & \\
\hline 10 & 0.540 & 203 & 0.039 & 9.096 & 0.900 & 0.943 & $* * *$ & \\
\hline 12 & 0.580 & 130 & 0.049 & 8.055 & 0.900 & 0.943 & $* * *$ & \\
\hline 15 & 0.640 & 156 & 0.045 & 10.336 & 0.900 & 0.943 & $* * *$ & \\
\hline 17 & 0.770 & 653 & 0.022 & 30.791 & 0.900 & 0.943 & $* * *$ & \\
\hline Mean/Total & 0.663 & 2782 & 0.011 & 46.386 & 0.900 & 0.943 & 1.000 & 0.780 \\
\hline
\end{tabular}

Variance $(a)=0.0000000 ;$ Variance $(b)=0.0000000 ;$ Variance $(c)=0.0000000$

Table 5: Compliance (Correlation Artifact Distribution Analysis)

\begin{tabular}{lccc}
\hline \multicolumn{1}{c}{ Mean } & $=$ & Bare Bones 0.66268 & Corrected 0.78049 \\
\hline Hypothesis-The Case Is Homogeneous; i.e., No Moderators & & & \\
Total Variance & $=$ & 0.0142251 & 0.0197325 \\
Error Variance & $=$ & 0.0019340 & 0.0026827 \\
Residual Variance & $=$ & 0.0122912 & 0.0170498 \\
$\%$ of Total Variance Accounted for by Artifacts & $=$ & 13.60 & 13.60 \\
Chi Square (16 df) & $=$ & 125.04 & 125.04 \\
\hline Number of Studies=17; Total Sample Size=2,782; Raw (unweighted Mean=0.39882 & \\
\hline
\end{tabular}

Table 6: Altruism (Moderator Group = Domestic)

\begin{tabular}{|c|c|c|c|c|c|c|c|c|}
\hline Study & $r$ & $N$ & $S E$ & $t$ & $a$ & $b$ & $c$ & $r c$ \\
\hline 2 & 0.740 & 98 & 0.054 & 10.780 & 0.906 & 0.943 & $* * *$ & \\
\hline 3 & 0.310 & 252 & 0.034 & 5.156 & 0.906 & 0.943 & $* * *$ & \\
\hline 4 & 0.680 & 475 & 0.025 & 20.170 & 0.906 & 0.943 & $* * *$ & \\
\hline 6 & 0.770 & 261 & 0.033 & 19.422 & 0.906 & 0.943 & $* * *$ & \\
\hline 7 & 0.350 & 67 & 0.066 & 3.012 & 0.906 & 0.943 & $* * *$ & \\
\hline 9 & 0.750 & 367 & 0.028 & 21.663 & 0.906 & 0.943 & $* * *$ & \\
\hline 10 & 0.450 & 114 & 0.050 & 5.333 & 0.906 & 0.943 & $* * *$ & \\
\hline 11 & 0.520 & 203 & 0.038 & 8.631 & 0.906 & 0.943 & $* * *$ & \\
\hline 13 & 0.570 & 130 & 0.047 & 7.849 & 0.906 & 0.943 & $* * *$ & \\
\hline 16 & 0.750 & 85 & 0.058 & 10.330 & 0.906 & 0.943 & $* * *$ & \\
\hline 17 & 0.770 & 156 & 0.043 & 14.976 & 0.906 & 0.943 & $* * *$ & \\
\hline 19 & 0.840 & 653 & 0.021 & 39.500 & 0.906 & 0.943 & $* * *$ & \\
\hline Mean/Total & 0.682 & 2963 & 0.010 & 50.488 & 0.906 & 0.943 & 1.000 & 0.799 \\
\hline
\end{tabular}

Variance $(\mathrm{a})=0.0000000 ;$ Variance $(\mathrm{b})=-0.0000000 ;$ Variance $(\mathrm{c})=0.0000000$ 
Table 7: Altruism (Correlation Artifact Distribution Analysis)

\begin{tabular}{lcc}
\hline Mean & $=$ & Bare Bones 0.68239 \\
\hline Hypothesis-The Case Is Homogeneous; i.e., No Moderators: & & Corrected 0.79879 \\
Total Variance & $=$ & 0.0269297 \\
Error Variance & $=$ & 0.0018427 \\
Residual Variance & $=$ & 0.0250870 \\
$\%$ of Total Variance Accounted for By Artifacts & $=$ & 6.84 \\
Chi Square (18 df) & $=$ & 277.67 \\
\hline Number of Studies=19; Total Sample Size=2,963; Raw (unweighted) Mean=0.43895 & \\
\hline
\end{tabular}

Table 8: Compliance (Moderator Group = Foreign)

\begin{tabular}{|c|c|c|c|c|c|c|c|c|}
\hline Study & $r$ & $N$ & $S E$ & $t$ & $a$ & $b$ & $c$ & $r c$ \\
\hline 1 & 0.700 & 195 & 0.042 & 13.617 & 0.900 & 0.943 & *** & \\
\hline 7 & 0.680 & 42 & 0.091 & 5.866 & 0.900 & 0.943 & $* * *$ & \\
\hline 11 & 0.820 & 63 & 0.074 & 11.189 & 0.900 & 0.943 & $* * *$ & \\
\hline 13 & 0.420 & 139 & 0.049 & 5.417 & 0.900 & 0.943 & $* * *$ & \\
\hline 14 & 0.470 & 142 & 0.049 & 6.300 & 0.900 & 0.943 & $* * *$ & \\
\hline 16 & 0.840 & 182 & 0.043 & 20.770 & 0.900 & 0.943 & $* * *$ & \\
\hline Mean/TotaL & 0.648 & 774 & 0.021 & 23.165 & 0.900 & 0.943 & 1.000 & 0.764 \\
\hline
\end{tabular}

Variance $(\mathrm{a})=-0.0000000 ;$ Variance $(\mathrm{b})=-0.0000000 ;$ Variance $(\mathrm{c})=0.0000000$

Table 9: Compliance (Correlation Artifact Distribution Analysis)

\begin{tabular}{lcc}
\hline Mean & $=$ & Bare Bones 0.64834 \\
\hline Hypothesis_-The Case Is Homogeneous; i.e., No Moderators & Corrected 0.76359 \\
Total Variance & $=$ & 0.0273637 \\
Error Variance & $=$ & 0.0075457 \\
Residual Variance & $=$ & 0.0198179 \\
\% of Total Variance Accounted for By Artifacts & $=$ & 27.58 \\
Chi Square (16 df) & $=$ & 61.65 \\
\hline
\end{tabular}

Number of Studies=17; Total Sample Size=774; Raw (unweighted) Mean=0.23118

Table 10: Altruism (Moderator Group = Foreign)

\begin{tabular}{|c|c|c|c|c|c|c|c|c|}
\hline Study & $r$ & $N$ & $S E$ & $t$ & $a$ & $b$ & $c$ & $r c$ \\
\hline 1 & 0.610 & 195 & 0.048 & 10.695 & 0.906 & 0.943 & $* * *$ & \\
\hline 8 & 0.590 & 42 & 0.104 & 4.622 & 0.906 & 0.943 & $* * *$ & \\
\hline 12 & 0.840 & 63 & 0.084 & 12.091 & 0.906 & 0.943 & $* * *$ & \\
\hline 14 & 0.330 & 139 & 0.056 & 4.092 & 0.906 & 0.943 & $* * *$ & \\
\hline 15 & 0.310 & 142 & 0.056 & 3.858 & 0.906 & 0.943 & $* * *$ & \\
\hline 18 & 0.860 & 182 & 0.049 & 22.611 & 0.906 & 0.943 & $* * *$ & \\
\hline Mean/Total & 0.581 & 776 & 0.024 & 19.373 & 0.906 & 0.943 & 1.000 & 0.680 \\
\hline
\end{tabular}

Variance $(a)=0.0000000 ;$ Variance $(b)=-0.0000000 ;$ Variance $(c)=0.0000000$

Table 11: Altruism (Correlation Artifact Distribution Analysis)

\begin{tabular}{lcc}
\hline Mean & = & Bare Bones 0.58061 \\
\hline Hypothesis_The Case Is Homogeneous; i.e., No Moderators & Corrected 0.67964 \\
Total Variance & 0.0494900 \\
Error Variance & 0.0678131 \\
Residual Variance & $=0.0110293$ \\
\% of Total Variance Accounted for by Artifacts & 0.0384607 \\
Chi Square (18 df) & $=$ & 22.29 \\
\hline Number of Studies=19; Total Sample Size=776; Raw (unweighted) Mean=0.18632 & & 85.26 \\
\hline
\end{tabular}

\section{Supervisory Status Moderator Analysis}

A total of four studies identified supervisors in their sample demographics $(\mathrm{K}=7, \mathrm{~N}=1,450)$ for organizational citizenship behavior (compliance). The mean for the bare bones analysis was 0.72 and for the corrected analysis was 0.85 . A $95 \%$ confidence interval places the true corrected correlation between 0.70 and 0.82 and the bare bones correlation between 0.75 and 0.88 . 
A total of five studies identified supervisors in their sample demographics $(K=5, N=1,536)$ for organizational citizenship behavior (altruism). The mean for the bare bones analysis was 0.73 and for the corrected analysis was 0.85 . A $95 \%$ confidence interval places the true corrected correlation between 0.70 and 0.82 and the bare bones correlation between 0.75 and 0.88 . A total of four studies identified subordinates in their sample demographics ( $K=4, N=754$ ) for organizational citizenship behavior (compliance). The mean for the bare bones analysis was 0.54 and for the corrected analysis was 0.63 . A 95\% confidence interval places the true corrected correlation between 0.49 and 0.57 and the bare bones correlation between 0.59 and 0.69. A total of five studies identified subordinates in their sample demographics $(K=5, N=851)$ for organizational citizenship behavior (altruism). The mean for the bare bones analysis was 0.55 and for the corrected analysis was 0.64 . A 95\% confidence interval places the true corrected correlation between 0.50 and 0.59 and the bare bones correlation between 0.60 and 0.70 .

A total of nine studies identified both supervisors and subordinates in their sample demographics $(K=9, N=$ $1,369)$ for organizational citizenship behavior (compliance). The mean for the bare bones analysis was 0.66 and for the corrected analysis was 0.78 . A 95\% confidence interval places the true corrected correlation between 0.63 and 0.74 and the bare bones correlation between 0.69 and 0.82 . A total of nine studies identified both supervisors and subordinates in their sample demographics $(K=9, N=1,371)$ for organizational citizenship behavior (altruism). The mean for the bare bones analysis was 0.66 and for the corrected analysis was 0.77 . A $95 \%$ confidence interval places the true corrected correlation between 0.63 and 0.74 and the bare bones correlation between 0.69 and 0.81 . The full data tables are found in Tables 12 through 23.

Table 12: Compliance (Moderator Group = Supervisors)

\begin{tabular}{ccccccccc}
\hline Study & $\boldsymbol{r}$ & $\boldsymbol{N}$ & $\boldsymbol{S E}$ & $\boldsymbol{t}$ & $\boldsymbol{a}$ & $\boldsymbol{b}$ & $\boldsymbol{c}$ & $\boldsymbol{r}$ \\
\hline 1 & 0.700 & & 195 & 0.035 & 13.617 & 0.900 & 0.943 & $* * *$ \\
4 & 0.700 & & 475 & 0.022 & 21.318 & 0.900 & 0.943 & $* * *$ \\
9 & 0.550 & & 114 & 0.045 & 6.969 & 0.900 & 0.943 & $* * *$ \\
17 & 0.770 & & 653 & 0.019 & 30.791 & 0.900 & 0.943 & $* * *$ \\
Mean/Total & 0.720 & 1450 & 0.013 & 39.043 & 0.900 & 0.943 & 1.000 & 0.848 \\
\hline
\end{tabular}

Variance $(\mathrm{a})=-0.0000000 ;$ Variance $(\mathrm{b})=-0.0000000 ;$ Variance $(\mathrm{c})=0.0000000$

Table 13: Compliance (Correlation Artifact Distribution Analysis)

\begin{tabular}{lccc}
\hline Mean & $=$ & Bare Bones 0.72002 & Corrected 0.84802 \\
\hline Hypothesis-The Case Is Homogeneous; i.e., No Moderators: & & & \\
Total Variance & $=$ & 0.0036029 & 0.0049977 \\
Error Variance & $=$ & 0.0027512 & 0.0038163 \\
Residual Variance & $=$ & 76008517 & 0.0011814 \\
\% of Total Variance Accounted for by Artifacts & $=$ & 22.26 & 76.36 \\
Chi Square (16 df) & & & \\
\hline Number of Studies=17; Total Sample Size=1,450; Raw (unweighted) Mean=0.16000 & & & \\
\hline
\end{tabular}

Table 14: Altruism (Moderator Group = Supervisors)

\begin{tabular}{|c|c|c|c|c|c|c|c|c|}
\hline Study & $r$ & $N$ & $S E$ & $t$ & $a$ & $b$ & $c$ & $r c$ \\
\hline 1 & 0.610 & 195 & 0.034 & 10.695 & 0.906 & 0.943 & $* * *$ & \\
\hline 4 & 0.680 & 475 & 0.022 & 20.170 & 0.906 & 0.943 & $* * *$ & \\
\hline 10 & 0.450 & 114 & 0.044 & 5.333 & 0.906 & 0.943 & $* * *$ & \\
\hline 19 & 0.840 & 653 & 0.018 & 39.500 & 0.906 & 0.943 & $* * *$ & \\
\hline Mean/Total & 0.727 & 1536 & 0.012 & 40.926 & 0.906 & 0.943 & 1.000 & 0.850 \\
\hline
\end{tabular}

Variance $(\mathrm{a})=-0.0000000 ;$ Variance $(\mathrm{b})=-0.0000000 ;$ Variance $(\mathrm{c})=0.0000000$ 
Table 15: Altruism (Correlation Artifact Distribution Analysis)

\begin{tabular}{|c|c|c|c|}
\hline Mean & $=$ & Bare Bones 0.72656 & Corrected 0.85049 \\
\hline \multicolumn{4}{|c|}{ Hypothesis-The Case Is Homogeneous; i.e., No Moderators } \\
\hline Total Variance & $=$ & 0.0136735 & 0.0187359 \\
\hline Error Variance & $=$ & 0.0027916 & 0.0038252 \\
\hline$\%$ of Total Variance Accounted for by Artifacts & $=$ & 20.42 & 20.42 \\
\hline Chi Square (18 df) & $=$ & 93.06 & 93.06 \\
\hline
\end{tabular}

Table 16: Compliance (Moderator Group = Subordinates)

\begin{tabular}{|c|c|c|c|c|c|c|c|c|}
\hline Study & $r$ & $N$ & $S E$ & $t$ & $a$ & $b$ & $c$ & $r c$ \\
\hline 3 & 0.450 & 252 & 0.045 & 7.967 & 0.900 & 0.943 & $* * *$ & \\
\hline 10 & 0.540 & 203 & 0.050 & 9.096 & 0.900 & 0.943 & $* * *$ & \\
\hline 12 & 0.580 & 130 & 0.063 & 8.055 & 0.900 & 0.943 & $* * *$ & \\
\hline Mean/Total & 0.537 & 754 & 0.026 & 17.098 & 0.900 & 0.943 & 1.000 & 0.633 \\
\hline
\end{tabular}

Variance (a) $=0.0000000 ;$ Variance $(b)=0.0000000 ;$ Variance $(c)=0.0000000$

Table 17: Compliance (Correlation Artifact Distribution Analysis)

\begin{tabular}{|c|c|c|c|}
\hline Mean & $=$ & Bare Bones 0.53738 & Corrected 0.63291 \\
\hline \multicolumn{4}{|c|}{ Hypothesis-The Case Is Homogeneous; i.e., No Moderators } \\
\hline Total Variance & $=$ & 0.0051349 & 0.0071229 \\
\hline Error Variance & $=$ & 0.0116679 & 0.0161851 \\
\hline$\%$ of Total Variance Accounted for by Artifacts & $=$ & 227.23 & 227.23 \\
\hline Chi Square (16 df) & $=$ & 7.48 & 7.48 \\
\hline
\end{tabular}

Table 18: Altruism (Moderator Group $=$ Subordinates)

\begin{tabular}{|c|c|c|c|c|c|c|c|c|}
\hline Study & $r$ & $N$ & $S E$ & $t$ & $a$ & $b$ & $c$ & $r c$ \\
\hline 3 & 0.310 & 252 & 0.044 & 5.156 & 0.906 & 0.943 & $* * *$ & \\
\hline 5 & 0.840 & 96 & 0.072 & 15.010 & 0.906 & 0.943 & $* * *$ & \\
\hline 11 & 0.520 & 203 & 0.049 & 8.631 & 0.906 & 0.943 & $* * *$ & \\
\hline 17 & 0.770 & 156 & 0.056 & 14.976 & 0.906 & 0.943 & $* * *$ & \\
\hline Mean/Total & 0.548 & 851 & 0.024 & 18.656 & 0.906 & 0.943 & 1.000 & 0.641 \\
\hline
\end{tabular}

Variance $(\mathrm{a})=-0.0000000 ;$ Variance $(\mathrm{b})=-0.0000000 ;$ Variance $(\mathrm{c})=0.0000000$

Table 19: Altruism (Correlation Artifact Distribution Analysis)

\begin{tabular}{|c|c|c|c|}
\hline Mean & $=$ & Bare Bones 0.54751 & Corrected 0.64090 \\
\hline \multicolumn{4}{|c|}{ Hypothesis-The Case Is Homogeneous; i.e., No Moderators } \\
\hline Total Variance & $=$ & 0.0362709 & 0.0496997 \\
\hline Error Variance & $=$ & 0.0111973 & 0.0153429 \\
\hline Residual Variance & $=$ & 0.0250736 & 0.0343568 \\
\hline$\%$ of Total Variance Accounted for by Artifacts & $=$ & 30.87 & 30.87 \\
\hline Chi Square (18 df) & $=$ & 61.55 & 61.55 \\
\hline
\end{tabular}


Table 20: Compliance (Moderator Group = Supervisors and Subordinates)

\begin{tabular}{|c|c|c|c|c|c|c|c|c|}
\hline Study & $r$ & $N$ & $S E$ & $t$ & $a$ & $b$ & $c$ & $r c$ \\
\hline 2 & 0.680 & 98 & 0.057 & 9.087 & 0.900 & 0.943 & **** & \\
\hline 5 & 0.850 & 261 & 0.035 & 25.968 & 0.900 & 0.943 & $* * *$ & \\
\hline 6 & 0.400 & 67 & 0.069 & 3.519 & 0.900 & 0.943 & $* * *$ & \\
\hline 8 & 0.620 & 367 & 0.029 & 15.097 & 0.900 & 0.943 & $* * *$ & \\
\hline 11 & 0.820 & 63 & 0.071 & 11.189 & 0.900 & 0.943 & $* * *$ & \\
\hline 13 & 0.420 & 139 & 0.048 & 5.417 & 0.900 & 0.943 & $* * *$ & \\
\hline 14 & 0.470 & 142 & 0.047 & 6.300 & 0.900 & 0.943 & $* * *$ & \\
\hline 16 & 0.840 & 182 & 0.042 & 20.770 & 0.900 & 0.943 & $* * *$ & \\
\hline Mean/Total & 0.662 & 1369 & 0.015 & 32.288 & 0.900 & 0.943 & 1.000 & 0.780 \\
\hline
\end{tabular}

Variance $(a)=-0.0000000 ;$ Variance $(b)=0.0000000 ;$ Variance $(c)=0.0000000$

Table 21: Compliance (Correlation Artifact Distribution Analysis)

\begin{tabular}{|c|c|c|c|}
\hline \multicolumn{4}{|c|}{ Table 21: Compliance (Correlation Artifact Distribution Analysis) } \\
\hline Mean & $=$ & Bare Bones 0.66218 & Corrected 0.77990 \\
\hline \multicolumn{4}{|c|}{ Hypothesis-The Case Is Homogeneous; i.e., No Moderators } \\
\hline Total Variance & $=$ & 0.0258672 & 0.0358818 \\
\hline Residual Variance & $=$ & 0.0219026 & 0.0303824 \\
\hline$\%$ of Total Variance Accounted for by Artifacts & $=$ & 15.33 & 15.33 \\
\hline Chi Square $(16 \mathrm{df})$ & $=$ & 110.92 & 110.92 \\
\hline
\end{tabular}

Table 22: Altruism (Moderator Group = Supervisors and Subordinates)

\begin{tabular}{|c|c|c|c|c|c|c|c|c|}
\hline Study & $r$ & $N$ & $S E$ & $t$ & $a$ & $b$ & $c$ & $r c$ \\
\hline 2 & 0.740 & 98 & 0.057 & 10.780 & 0.906 & 0.943 & $* * *$ & \\
\hline 6 & 0.770 & 261 & 0.035 & 19.422 & 0.906 & 0.943 & $* * *$ & \\
\hline 7 & 0.350 & 67 & 0.070 & 3.012 & 0.906 & 0.943 & $* * *$ & \\
\hline 9 & 0.750 & 367 & 0.030 & 21.663 & 0.906 & 0.943 & $* * *$ & \\
\hline 12 & 0.840 & 63 & 0.072 & 12.091 & 0.906 & 0.943 & $* * *$ & \\
\hline 14 & 0.330 & 139 & 0.048 & 4.092 & 0.906 & 0.943 & $* * *$ & \\
\hline 15 & 0.310 & 142 & 0.048 & 3.858 & 0.906 & 0.943 & $* * *$ & \\
\hline 18 & 0.860 & 182 & 0.042 & 22.611 & 0.906 & 0.943 & $* * *$ & \\
\hline Mean/Total & 0.659 & 1371 & 0.015 & 31.976 & 0.906 & 0.943 & 1.000 & 0.771 \\
\hline
\end{tabular}

Variance $(a)=0.0000000 ;$ Variance $(b)=0.0000000 ;$ Variance $(c)=0.0000000$

Table 23: Altruism (Correlation Artifact Distribution Analysis)

\begin{tabular}{|c|c|c|c|}
\hline Mean & $=$ & Bare Bones 0.65885 & Corrected 0.77123 \\
\hline \multicolumn{4}{|c|}{ Hypothesis_-The Case Is Homogeneous; i.e., No Moderators } \\
\hline Total Variance & $=$ & 0.0405493 & 0.0555622 \\
\hline Error Variance & $=$ & 0.0045008 & 0.0061672 \\
\hline Residual Variance & $=$ & 0.0360485 & 0.0493950 \\
\hline$\%$ of Total Variance Accounted for by Artifacts & $=$ & 11.10 & 11.10 \\
\hline Chi Square (18 df) & $=$ & 171.18 & 171.18 \\
\hline
\end{tabular}

\section{Employee Tenure Moderator Analysis}

In five studies (altruism) the sample employment tenure was less than 5 years $(K=5, N=722)$. These studies also revealed a large correlation between organizational citizenship behavior (altruism) and leader-member exchange. The mean of the bare bones analysis was 0.57 and for the corrected analysis was 0.67 . A $95 \%$ confidence interval places the true corrected correlation between 0.52 and 0.61 and the bare bones correlation between 0.62 and 0.73 .

In 11 studies (compliance) the sample employment tenure was greater than 5 years $(K=11, N=2,793)$. The studies revealed a large correlation between organizational citizenship behavior (compliance) and leader-member 
exchange. The mean of the bare bones analysis was 0.68 and for the corrected analysis was 0.81 . A $95 \%$ confidence interval places the true corrected correlation between 0.67 and 0.78 and the bare bones correlation between 0.70 and 0.83 .

In 11 studies (altruism) the sample employment tenure was greater than 5 years $(K=11, N=2,795)$. The studies revealed a large correlation between organizational citizenship behavior (altruism) and leader-member exchange. The mean of the bare bones analysis was 0.68 and for the corrected analysis was 0.80 . A $95 \%$ confidence interval places the true corrected correlation between 0.66 and 0.77 and the bare bones correlation between 0.70 and 0.82. The full data tables are found in Tables 24 through 31.

Table 24: Employee Tenure Moderator Analysis-Compliance (Moderator Group > 5 years tenure)

\begin{tabular}{|c|c|c|c|c|c|c|c|c|}
\hline Study & $r$ & $N$ & $S E$ & $t$ & $a$ & $b$ & $c$ & $r c$ \\
\hline 1 & 0.700 & 195 & 0.038 & 13.617 & 0.900 & 0.943 & $* * *$ & \\
\hline 3 & 0.450 & 252 & 0.034 & 7.967 & 0.900 & 0.943 & $* * *$ & \\
\hline 4 & 0.700 & 475 & 0.024 & 21.318 & 0.900 & 0.943 & $* * *$ & \\
\hline 6 & 0.400 & 67 & 0.065 & 3.519 & 0.900 & 0.943 & $* * *$ & \\
\hline 8 & 0.620 & 367 & 0.028 & 15.097 & 0.900 & 0.943 & $* * *$ & \\
\hline 11 & 0.820 & 63 & 0.067 & 11.189 & 0.900 & 0.943 & $* * *$ & \\
\hline 12 & 0.580 & 130 & 0.047 & 8.055 & 0.900 & 0.943 & $* * *$ & \\
\hline 14 & 0.470 & 142 & 0.045 & 6.300 & 0.900 & 0.943 & $* * *$ & \\
\hline 16 & 0.840 & 182 & 0.039 & 20.770 & 0.900 & 0.943 & $* * *$ & \\
\hline 17 & 0.770 & 653 & 0.021 & 30.791 & 0.900 & 0.943 & $* * *$ & \\
\hline Mean/Total & 0.685 & 2793 & 0.010 & 49.354 & 0.900 & 0.943 & 1.000 & 0.806 \\
\hline
\end{tabular}

Variance $(\mathrm{a})=-0.0000000 ;$ Variance $(\mathrm{b})=0.0000000 ;$ Variance $(\mathrm{c})=0.0000000$

Table 25: Compliance (Correlation Artifact Distribution Analysis)

\begin{tabular}{lcc}
\hline Mean & Bare Bones 0.68476 & Corrected 0.80649 \\
\hline Hypothesis-The Case Is Homogeneous; i.e., No Moderators & & \\
Total Variance & 0.0166162 \\
Error Variance & 0.0230492 & 0.0017274 \\
Residual Variance & 0.0148887 \\
\% of Total Variance Accounted for by Artifacts & 10.40 \\
Chi Square (16 df) & 0.0206530 & 10.40 \\
\hline Number of Studies=17; Total Sample Size=2,793; Raw (unweighted) Mean=0.68476 & 163.52 \\
\hline
\end{tabular}

Table 26: Altruism (Moderator Group- = Greater than 5 years tenure)

\begin{tabular}{|c|c|c|c|c|c|c|c|c|}
\hline Study & $r$ & $N$ & $S E$ & $t$ & $a$ & $b$ & $c$ & $r c$ \\
\hline 1 & 0.610 & 195 & 0.039 & 10.695 & 0.906 & 0.943 & $* * *$ & \\
\hline 3 & 0.310 & 252 & 0.034 & 5.156 & 0.906 & 0.943 & $* * *$ & \\
\hline 4 & 0.680 & 475 & 0.025 & 20.170 & 0.906 & 0.943 & $* * *$ & \\
\hline 7 & 0.350 & 67 & 0.066 & 3.012 & 0.906 & 0.943 & $* * *$ & \\
\hline 9 & 0.750 & 367 & 0.028 & 21.663 & 0.906 & 0.943 & $* * *$ & \\
\hline 12 & 0.840 & 63 & 0.068 & 12.091 & 0.906 & 0.943 & $* * *$ & \\
\hline 13 & 0.570 & 130 & 0.047 & 7.849 & 0.906 & 0.943 & $* * *$ & \\
\hline 15 & 0.310 & 142 & 0.045 & 3.858 & 0.906 & 0.943 & $* * *$ & \\
\hline 18 & 0.860 & 182 & 0.040 & 22.611 & 0.906 & 0.943 & $* * *$ & \\
\hline 19 & 0.840 & 653 & 0.021 & 39.500 & 0.906 & 0.943 & $* * *$ & \\
\hline Mean/Total & 0.680 & 2795 & 0.010 & 48.757 & 0.906 & 0.943 & 1.000 & 0.797 \\
\hline
\end{tabular}

Variance $(\mathrm{a})=-0.0000000 ;$ Variance $(\mathrm{b})=0.0000000 ;$ Variance $(\mathrm{c})=0.0000000$ 
Table 27: Altruism (Correlation Artifact Distribution Analysis)

\begin{tabular}{lcc}
\hline Mean & Bare Bones 0.68045 & Corrected 0.79652 \\
\hline Hypothesis_The Case Is Homogeneous; i.e., No Moderators & \\
Total Variance & 0.0329270 \\
Error Variance & $=$ & 0.0019736 \\
Residual Variance & $=$ & 0.0309534 \\
\% of Total Variance Accounted for by Artifacts & 5.99 & 0.0027043 \\
Chi Square (18 df) & 5.0424135 & 316.99 \\
\hline Number of Studies=19; Total Sample Size=2,795; Raw (unweighted) Mean=0.36263 & & \\
\hline
\end{tabular}

Table 28: Compliance (Moderator Group = Less than 5 years Tenure)

\begin{tabular}{|c|c|c|c|c|c|c|c|c|}
\hline Study & $r$ & $N$ & $S E$ & $t$ & $a$ & $b$ & $c$ & $r c$ \\
\hline 9 & .550 & 114 & 0.067 & 6.969 & 0.900 & 0.943 & **** & \\
\hline 10 & 0.540 & 203 & 0.050 & 9.096 & 0.900 & 0.943 & $* * *$ & \\
\hline 13 & 0.420 & 139 & 0.060 & 5.417 & 0.900 & 0.943 & $* * *$ & \\
\hline 15 & 0.640 & 156 & 0.057 & 10.336 & 0.900 & 0.943 & $* * *$ & \\
\hline Mean/Total & 0.540 & 625 & 0.029 & 15.602 & 0.900 & 0.943 & 1.000 & 0.636 \\
\hline
\end{tabular}

Variance $(\mathrm{a})=-0.0000000 ;$ Variance $(\mathrm{b})=-0.0000000 ;$ Variance $(\mathrm{c})=0.0000000$

Table 29: Compliance (Correlation Artifact Distribution Analysis)

\begin{tabular}{lcc}
\hline Mean & Bare Bones 0.54012 & Corrected 0.63613 \\
\hline Hypothesis_The Case Is Homogeneous; i.e., No Moderators & & \\
Total Variance & 0.0058363 \\
Error Variance & 0.0080959 & 0.0140265 \\
Residual Variance & 0.0194570 & 0.000000 \\
$\%$ of Total Variance Accounted for by Artifacts & $=0000000$ & 240.33 \\
Chi Square (16 df) & $=0.33$ & 7.07 \\
\hline Number of Studies=17; Total Sample Size=625; Raw (unweighted) Mean=0.12647 & & \\
\hline
\end{tabular}

Table 30: Altruism (Moderator Group = Less than 5 years Tenure)

\begin{tabular}{|c|c|c|c|c|c|c|c|c|}
\hline Study & $r$ & $N$ & $S E$ & $t$ & $a$ & $b$ & $c$ & $r c$ \\
\hline 5 & 0.840 & 96 & 0.069 & 15.010 & 0.906 & 0.943 & **** & \\
\hline 10 & 0.450 & 114 & 0.064 & 5.333 & 0.906 & 0.943 & $* * *$ & \\
\hline 11 & 0.520 & 203 & 0.048 & 8.631 & 0.906 & 0.943 & $* * *$ & \\
\hline 14 & 0.330 & 139 & 0.057 & 4.092 & 0.906 & 0.943 & $* * *$ & \\
\hline 17 & 0.770 & 156 & 0.054 & 14.976 & 0.906 & 0.943 & $* * *$ & \\
\hline Mean/Total & 0.570 & 722 & 0.025 & 18.135 & 0.906 & 0.943 & 1.000 & 0.667 \\
\hline
\end{tabular}

Variance $(\mathrm{a})=0.0000000 ;$ Variance $(\mathrm{b})=-0.0000000 ;$ Variance $(\mathrm{c})=0.0000000$

Table 31: Altruism (Correlation Artifact Distribution Analysis)

\begin{tabular}{|c|c|c|c|}
\hline Mean & $=$ & Bare Bones 0.56982 & Corrected 0.66701 \\
\hline \multicolumn{4}{|c|}{ Hypothesis-The Case Is Homogeneous; i.e., No Moderators } \\
\hline Total Variance & $=$ & 0.0330106 & 0.0452324 \\
\hline Error Variance & $=$ & 0.0123255 & 0.0168889 \\
\hline Residual Variance & $=$ & 0.0206851 & 0.0283435 \\
\hline$\%$ of Total Variance Accounted for by Artifacts & $=$ & 37.34 & 37.34 \\
\hline Chi Square (18 df) & $=$ & 50.89 & 50.89 \\
\hline
\end{tabular}

The results of the meta-analysis of organizational citizenship behavior (both compliance and altruism) and leader-member exchange have found a large correlation between the two variables. Significant findings were located in the supervisor moderator. Although all moderators reported a high correlation, supervisor only was much higher than subordinate only, or both supervisor and subordinate when reviewing altruism. It would be beneficial to organizations to find out why this is so, thereby raising everyone's level of OCB. 


\section{DISCUSSION}

\section{Domestic/Foreign Moderator Analysis}

The results of the domestic and foreign moderator analysis revealed little difference between the two groups. There are other factors that might have influenced the correlation between organizational citizenship behavior and leader-member exchange. Because categorization guides subsequent information processing, the initial classification of a person can lay the groundwork for the dyadic relationship that will eventually develop. According to Gilbert (1989), social perceptions involve three steps: categorization, characterization of dispositional factors, and correction for situational influences. The implication of the information processing research for the development of LMX relationships is clear. Once labeled, it is difficult to change the initial impression of the perceiver and hence the nature of the relationship with that perceiver. The culture of the corporation does not seem to have an effect upon this fact.

\section{Supervisory Status Moderator Analysis}

The results of this moderator analysis seem to suggest that there is a high correlation between organizational citizenship behavior and leader-member exchange. From the review of literature, Lord and Maher (1991) have spelled out the importance of implicit theories in organizational contexts. They have asserted that values may provide justification for behavior, but that implicit theories actually drive behavior. Implicit theories often serve as a guide for the automatic processing of organizational information. When used in this manner, implicit theories act as cognitive filters that predispose people to think and act in a particular way (Lord \& Maher, 1991). Due to the large cognitive load that is often present in organizational settings, employees rely extensively on their implicit theories not just for the understanding of organizational culture, but also as a guide for their social interactions. These implicit theories are likely to be especially influential during the initial stages of the exchange relationship when uncertainty along several dimensions exists. In these situations, implicit theories serve as a standard of comparison for the behaviors exhibited by both the leader and the member. The first time the subordinate encounters a leader; he or she likely automatically compares the leader's behavior to an implicit leadership theory. If there is a match between the leader's behavior and the subordinate's implicit leadership theory, then two things should happen. First, this match should produce a positive affective reaction on the part of the subordinate. Second, the leader will most likely be classified into the appropriate cognitive leadership category. The same sort of process takes place from the leader's perspective, but with an implicit performance theory being used as a standard for comparison.

\section{Employee Tenure Moderator Analysis}

This analysis seems to demonstrate the high correlation between organizational citizenship behavior and leader-member exchange. The $95 \%$ confidence level for tenure greater than 5 years is slightly higher for both compliance and altruism as the $95 \%$ confidence level for tenure less than 5 years. The weighted mean for the bare bones analysis and the corrected analysis is also higher for tenure greater than 5 years for compliance and altruism. This has both managerial and financial implications that need to be investigated further.

\section{LIMITATIONS}

Although meta-analysis has many advantages as a technique for analyzing and summarizing the quantitative findings of a body of empirical research, it is by no means without problems and limitations. Meta-analysis results are only as good as the studies that are included in the meta-analysis. This meta-analysis was not able to correct for range restriction due to the failure of the studies analyzed to report the standard deviation in a consistent fashion. If there are no studies of high methodological quality in the research base, it can hardly be expected that aggregating their findings will yield valid and useful results. Meta-analysis must carefully observe and code the key features of the studies judged eligible for the meta-analysis that bear on the validity and credibility of their results (Lipsey \& Wilson, 2001). Even though the studies did not report the standard deviation consistently, other areas of the studies were considered of good quality. Multivariate analysis makes it possible to estimate the independent contribution of each methodological feature to the study results. If the methodological features are not neutral, those that are most influential must be identified and their net impact on summary effect sizes must be assessed. One approach is to fit 
weighted multiple regression models in which the various methodological features are used to predict effect size. The resulting unstandardized regression coefficients on the method variables represent the multiplier that weights each value on a method variable (Lipsey \& Wilson, 2001). As Lipsey and Wilson stated, if the best value is plugged in for each important method variable, the equation can be used to estimate the mean effect size that would be expected if all studies had the optimal combination of method features.

\section{FUTURE RESEARCH}

The high correlation between OCB and LMX raises questions that might be of further interest. Domestic and foreign businesses have many struggles, including takeovers, mergers, restructuring, acquisitions, and the economy. This can lead to many managerial and financial problems. A major challenge is how to foster organizational citizenship behavior within employees despite these struggles. Because there is such a high correlation between the variables that were studied in this analysis, a standardized instrument combining organizations citizenship behavior and leader-member exchange should be developed. This instrument should be sensitive enough to provide reliable scores for both across a number of contexts.

\section{CONCLUSION}

This meta-analytic study focused on the correlation between OCB and LMX. The results of the full study for compliance $(K=17, N=3,539)$ and altruism $(K=19, N=3,720)$ and moderator analysis revealed large effect sizes in all moderators studied. This research illustrates several implications of leaders in organizations that directly affect organizational citizenship behavior. High leader-member exchange results in an increase in both altruism and compliance organizations citizenship behavior. This study adds to the research focusing on the positive dyadic relationship between the leader and the member or the supervisor and the subordinate, as opposed to the traits, behaviors, situational styles of the leader, or any other variables.

\section{REFERENCES}

1. Bateman, T. S. \& Organ, D. W. (1983). Job satisfaction and the good solder: The relationship between affect and employee "citizenship." Academy of Management Journal, 26, 587-595.

2. Blau, P. M. (1964). Exchange and power in social life. New York: John Wiley \& Sons.

3. Brief, A. P. \& Motowidle, S. J. (1986). Prosocial organization behaviors. .Academy of Management Review, 2, 710-725.

4. Colquitt, J. A., LePine, J. A., \& Noe, R. A. (2000). Toward an integrative theory of training motivation: A metaanalytic path analysis of 20 years of research. Journal of Applied Psychology, 85, 678-707.

5. Dansereau, F., Jr., Graen, G., \& Haga, W. J. (1975). A vertical dyad linkage approach to leadership within formal organizations: A longitudinal investigation of the role making process. Organizational Behavior and Human Performance, 13, 46-78.

6. Deluga, R. J. (1998). Leader-member exchange quality and effectiveness ratings: The role of subordinatesupervisor conscientiousness similarity. Group and Organization Management, 23(2), 189-216.

7. Dienesch, R. M. \& Linden, R. C. (1986) Leader-member exchange model of leadership: A critique and further development. Academy of Management Review, 11 (3), 618-634.

8. Gerstner, C. R. \& Day, D. V. (1997). Meta-analytic review of leader-member exchange theory: Correlates and construct issues. Journal of Applied Psychology, 82(6), 827-844.

9. Gilbert, D. T. (1989). Thinking lightly about others: automatic components of the social inference process. In J.S. Uleman \& J. A. Bargh (Eds.), Unintended thought (pp. 189-209). New York: Guilford Press.

10. Graen, G. B. (1976). Role making processes within complex organizations. In M. D. Dunnette (Ed.), Handbook of industrial and organizational psychology (pp. 1201-1245). Chicago: Rand McNally.

11. Graen, G. \& Cashman, J. F. (1975). A role-making model of leadership in formal organizations: A developmental approach. In James G. Hunt \& Lars L. Larson (Eds.). Leadership frontiers (pp. 143-165). Kent, OH: Kent State University Press.

12. Graen, G. B., Novak, M., \& Sommerkamp, P. (1982). The effects of leader-member exchange and job design on productivity and job satisfaction: Testing a dual attachment model. Organizational Behavior and Human Performance, 30, 109-131.

13. Graen, G. B. \& Scandura, T. A. (1987). Toward a psychology of dyadic organizing. In B.M. Staw \& L.L. 
Cummings (Eds.). Research in organizational behavior (pp. 175--208). Greenwich, CT: JAI Press.

14. Graen, G. \& Schiemann, W. (1978). Leader-member agreement: A vertical dyad linkage approach. Journal of Applied Psychology, 63, 206-212.

15. Graen, G. B. \& Uhl-Bien, M. (1995). Relationship-based approach to leadership: Development of leader-member exchange (LMX) theory of leadership over 25 years: Applying a multi-level multi-domain perspective. Leadership Quarterly, 6(2), 219-247.

16. Hogan, J., Hogan, R., \& Busch, C. (1984). How to measure service orientation. Journal of Applied Psychology, 40, $121-137$.

17. House, R. J., \& Aditya, R.N. (1997). The social scientific study of leadership: Quo Vadis? Journal of Management, 23(3), 409-473.

18. Hunter, J. E. \& Schmidt, F. L. (1990). Methods of meta-analysis: Correcting error and bias in research findings. Newbury Park, CA: Sage.

19. Karambayya, R. (1989). Organizational citizenship behavior: Contextual predictors and organizational consequences. Unpublished doctoral dissertation, Northwestern University, Evanston, IL.

20. Katz, D. \& Kahn, R. L. (1978). The social psychology of organizations. (2nd ed.). New York: Wiley \& Sons.

21. Kozlowski, S. W. \& Doherty, M. L. (1989). Integration of climate and leadership: Examination of a neglected issue. Journal of Applied Psychology, 74, 546-553.

22. Linden, R. C. \& Graen, G. (1980). Generalizability of the vertical dyad linkage model of leadership. Academy of Management Journal, 23, 451-465.

23. Linden, R. C., Wayne, S. J., \& Stilwell, D. (1993). A longitudinal study on the early development of leadermember exchanges. Journal of Applied Psychology, 78, 662-674.

24. Lipsey, M. W. \& Wilson, D. B. (2001). Practical meta-analysis. Thousand Oaks, CA: Sage.

25. Lord, R. G. \& Maher, K. J. (1991). Leadership and information processing: Linking perceptions and performance. New York: Routledge.

26. Organ, D. W. (1988). Organizational citizenship behavior: The good soldier syndrome. Lexington, MA: Lexington Books.

27. Organ, D. W. (1990). The motivational basis of organizational behavior. In B.M. Staw \& L.L. Cummings (Eds.). Research in organizational behavior: Vol. 12 (pp. 43-72). NY: JAI Press.

28. Organ, D. W. \& Konovsky, M. (1989). Cognitive versus affective determinants of organizational citizenship behavior. Journal of Applied Psychology, 74(1), 157-164.

29. Puffer, S. M. (1987). Prosocial behavior, noncompliant behavior and work performance among salespeople. Journal of Applied Psychology, 72(4). 615-621.

30. Ree, M. \& Stauffer, J. (1996). MetaWin [Computer software]. Brooks AFB, TX: U.S. Air Force Laboratory, Human Resource Directorate.

31. Rosch, E. (1978). Principles of categorization. In E. Rosch \& B.B. Lloyd (Eds.), Cognition and categorization (pp. 21-48). Hillsdale, NJ: Erlbaum.

32. Scandura, T. A. \& Graen, G. B. (1984). Moderating effects of initial leader-member exchange status on the effects of a leadership intervention. Journal of Applied Psychology, 69(3), 428-436.

33. Smith, C. A., Organ, D. W., \& Near, J. P. (1983). Organizational citizenship behavior: Its nature and antecedents. Journal of Applied Psychology, 68, 653-663.

34. Snyder, R. A., Williams, R. R., \& Cashman, J. F. (1984). Age, tenure, and work perceptions as predictors of reactions to performance feedback. Journal of Psychology, 116, 11-21.

35. Tansky, J. (1993). Justice and organizational citizenship behavior: What is the relationship? Employee Responsibilities and rights Journal, 4(1), 51-59.

36. Turban, D. B., Jones, A. P., \& Rozelle, R. M. (1990) Influences of supervisor liking of a subordinate and the reward context on the treatment and evaluation of that subordinate. Motivation and Emotion, 14, $215-233$.

37. Vecchio, R. P. (1982). A further test of leadership effects due to between-group and within-group variation. Journal of Applied Psychology, 67, 200-208.

38. Vecchio, R. \& Gobdel, B. (1984). The vertical dyad linkage model of leadership: Problems and prospects. Organizational Behavior and Human Performance, 34, 5-20.

39. Wayne, S. J. \& Ferris, G. R. (1990). Influence tactics, affect, and exchange quality in supervisor-subordinate interactions: A laboratory experiment and field study. Journal of Applied Psychology, 75(5), 487-499.

40. Zajonc, R. B. (1980). Feeling and thinking: Preferences need no inferences. American Psychologist, 35, $151-175$. 